\title{
Critical Polyalkane, Polyether, and Polysilicone Structure Differences: Consideration of Polymer Forces from the OPLS-AA Standpoint
}

\author{
Mongelli GF* \\ Department of Chemical Engineering, Case Western Reserve University, Cleveland, USA
}

\begin{abstract}
The OPLS-AA force field is well established in determining the bulk properties of molecules from molecular parameterizations. However, the comparison of such derived properties from high performance computing research has not extended to determine their applicability or breakdown in polyalkane, polyether and polysilicone materials, specifically in the context of surface activity. This letter highlights the differences in these structures attractive and repulsive forces while detailing the distances between charge centers. This paper describes the types of interactions within the OPLS-AA force field that explain polyether and polysilicone material solvophilicity, with particular focus on mixed solvent systems. It details how the solvophilicity varies with the relative strength of interactions for these materials at various alcohol contents.
\end{abstract}

Keywords: Polymer; Polyethers; Polysilicones; Materials; Entropy

\section{Introduction}

Recently the parameterization of many common liquid properties to an atomistic level has received significant research attention [1-6]. Understanding how these OPLS-AA parameterizations of individual atoms predict molecular behavior is critical to design of molecules with desirable properties such as foaming capability. Even more fundamentally, and prior to that goal, understanding which attributes of parameterizations lead to surfactantability is key. The study of polymeric materials is a key first step of tractable complexity. This study specifically presents the OPLS-AA potentials in the context of study of polyalkanes, polyethers and polysilicones together in one place with those of the alcohol co-solvents. This manuscript then highlights some noteworthy structural differences.

Experimental studies of the surface activity and structure of polyalkane, polyether, and polysilicone materials have been of increasingly interest [7]. Others have sought mathematical descriptions, but this work does not consider the impact of each atom in the molecular structure has on the surface activity, instead they treat macroparticle colloid surfaces within a solvent [8]. These materials are the nonionic surfactants which make up a multi-billion dollar annual shampoo, shaving cream, and detergent market globally [9]. Although some scholars have searched for structure function property relationships[10], the exact reason that these materials are surface active agents in the pattern of molecular structure variations in polyethers and polysilicones that nature takes has yet to be explored at a fundamental, first principles molecular dynamics level.

More specifically, the factors or characteristics of their molecular structure that lead to the surface tension reduction capability is presently unknown. This manuscript seeks to characterize these two topics using the optimized potential for liquid simulations for all atoms in mind (OPLS-AA). How the coefficients which describe particular atomistic interactions lead to ensemble potentials which translate into fundamental thermodynamic functionals - namely those associated with the laws of thermodynamics such as entropy, enthalpy, and free energy -- associated with different types of states in mixed solvent solutions with be thoroughly described and evaluated. The cases to be discussed are polymethyleneoxide (PMO), polyethyleneoxide (PEO), polypropylene oxide (PPO), and polydimethylsiloxane (PDMS). This manuscript combines the ensemble potentials used by several groups including Jorgensen [11], Sides [12], and Frischknecht and Curro [13].

\section{Discussion}

If the presence of carbon in the polymer structure is a solubilizing agent into alcohol co-solvated systems, then simply rating the number of carbons within the monomer structure and their relative charge strengths for each degree of polymerization will give a first order approximation of relative surface parameter, as it has in observing the surface parameter as a function of degree of polymerization. In such a case, the polymethyleneoxide will have a higher surface parameter than polyethyleneoxide at a certain alcohol content and degree of polymerization, based purely upon non-bonded constants. Additionally, polyethyleneoxide will have a higher surface parameter than polytrimethylenoxide and polypropyleneoxide. The latter two polymers have identical Lennard-Jones constants but different Coulombic and dihedral interactions. The entropy differences for these polymers are likely energetically small relative to Coulombic differences. Again, the polyethers have strong non-bonded constants which cause unfavorable interactions with water. The non-bonded constants of PEO result in the least repulsive interactions and lack of strain favor the bulk - most likely the former is more significant.

At high alcohol contents, much of the bulk system is composed of functional groups and constituent atoms that are functionally similar to those in the polymer. Such groups invoke the 'like dissolves like' formalism. The carbon portions of the polymers are attracted to the carbon portions of the solvents, more so when the carbon is quaternary than tertiary and tertiary than secondary and secondary than primary. This is because the LJ attractive forces remain a relatively distancedependent constant "control" in the OPLS-AA formalism, while the Carbon-Carbon repulsive Coulombic interactions diminish in higher

*Corresponding author: Mongelli GF, Department of Chemical Engineering, Case Western Reserve University, 10900 Euclid Ave., A.W. Smith 116, Cleveland, USA, Tel: 12163682000; E-mail: Gfm12@case.edu

Received December 14, 2016; Accepted December 31, 2016; Published January 10,2017

Citation: Mongelli GF (2017) Critical Polyalkane, Polyether, and Polysilicone Structure Differences: Consideration of Polymer Forces from the OPLS-AA Standpoint. J Material Sci Eng 6: 313. doi: 10.4172/2169-0022.1000313

Copyright: (c) 2017 Mongelli GF. This is an open-access article distributed under the terms of the Creative Commons Attribution License, which permits unrestricted use, distribution, and reproduction in any medium, provided the original author and source are credited. 
carbon coordination systems. In cases where carbon is bonded to oxygen, even the Coulombic portions of the polyether oxy-carbon and the polyalkyl carbon become attractive.

Another way to think about the recently presented idea is that the carbon-rich monomer structures will achieve a certain surface parameter value at a lower alcohol contents than a carbon-scarce monomer. The alcohol-dependent surface parameter behavior of polysilicone is difficult to predict because not only are the bonded, angular and dihedral constants very different from the poly-alkanes and the poly-ethers, but also there is little overlap in the non-bonded constants space for a purely empiricized input-output comparison. PDMS has one of the most flexible chains of any polymer, reflected in the low dihedral interaction energies. In fact some of the lowest in the entire OPLS-AA force field. This also may be the cause for it to have one of the lowest glass transition temperatures of all polymers. Therefore, there must be the strong entropic driving force to press it into the aqueous bulk than any in the polyalkanes poly-ethers or polysilicones discussed in this work. While PDMS has a large entropic driving force associated with low dihedral restriction, it does not readily take on bulk aqueous states due to strong net Coulombic and Lennard-Jones repulsions.

Several studies, including one by Kinoshita, indicate the potential number of $\mathrm{O}-\mathrm{H}$ and $\mathrm{H}-\mathrm{O}$ hydrogen bonding sites. Oxygen in can form two hydrogen bonds while $\mathrm{H}$ forms one [14]. However, the addition of oxygen into a polymer backbone typically removes two hydrogen that would be present had a carbon atom occupied the same site compared to a water molecule [15]. It is also critical to consider that the OPLS types of the backbone $\mathrm{C}$ and side $\mathrm{C}$ per monomer are different in the polyalkanes, polyethers and polysilicones [16]. Furthermore, the Coulombic charge associated with hydrogen depends significantly on the particular type of carbon to which it is attached $[17,18]$. The same is true for Oxygen. Sides et al. and Jorgensen et al. showed how carbon and hydrogen potentials vary when attached to carbon in silicon-based systems.

In describing polymer solvation, entropy differences are important when hydrogen bonding between polymers and solvents occurs in large numbers. Since $\mathrm{H}$ bonding is decreased in ethanol and other alcohols as the Coulombic charge on oxygens decreases, it is then expected that in polyethers, which have even less negative Coulombic charge on their oxygens than ethanol oxygens - but the same LJ interactions with other atoms as all other atoms with the same atomic number - that $\mathrm{H}$ bonding would then be decreased in those systems. Since it is the case that the LJ interactions are the same for oxygens in ethanol and oxygen in polyether, these forces can be eliminated from exclusively describing differences in the solubility of these materials in a single solvent mixture. For the case of decreased dihedral interaction systems, which remain insoluble in a particular mixture, the increased entropy the polymer may be less than the entropy increases associated with losses from lack of no-polymer-present solvent hydrogen bonding. In other words, hydrogen bonds represent extra enthalpic and entropic system stabilization.

The insolubility of some polyethers can be attributed to strong Coulombic repulsions with water, net breaking of hydrogen bonds between solvent atoms when placement in the bulk and relatively small entropy gains from 3D, solvent-coordinated states. Such repulsions lead to a phase separation token to surfactants. Additionally, hydrogens in alpha sites relative to oxygen have half the Coulombic positive charge of their saturated polyalkane analogues, leading to reduced hydrogen bonding strength, number of hydrogen bonds and attraction forces to the large negative charges present in both alcohol oxygens and water. PEO may have enhanced hydrogen bonding with the aqueous solvent relative to the other polyethers, large entropy gains due to solubilization caused by low dihedral restraint on backbone configurations, and the most favorable Coulombic interactions of the polyethers from the most secondary carbons per monomer unit. These are the factors that may lead to PEO solubility in pure aqueous systems.

The attractive Coulombic interactions between EtOH and PMO are between ethanol's oxygen and primary carbon paired with PMO's secondary and primary carbons as well as hydrogens - ranked in order of descending maximum negative charge for the former and positive charge in the latter. Another set of attractive Coulombic interactions exist in EtOH's alcohol hydrogen and secondary carbon paired with PMO's dialkyl ether oxygen.

The attractive Coulombic interactions between EtOH and PEO are identical in type but not number to those in PMO, with an additional ether-bonded carbon that has a very strong attraction to the EtOH alcohol oxygen. P3MO adds a secondary carbon group per monomer added. PPO has similar attractive interactions as the PMO and PEO but it adds a highly Coulombically EtOH-oxygen repulsive primary carbon group per degree of polymerization. This in addition to the dihedral restriction is the only possible reasons for PPO EtOH insolubility at lower contents than the others. Consideration of these subtleties allows us to consider the relative free energies of hydration. As much as these PPO groups are repelled by EtOH oxygens they are repelled even more strongly by the water oxygen which has a $25 \%$ larger negative Coulombic charge. This causes us to predict correctly that the PPO solubility in $\mathrm{HOH}$ is less than in $\mathrm{EtOH}$.

All of the charges on each of the solvent and solute polymer molecules sums to zero. By adding additional atoms to the monomeric structure, there is more total charge to redistribute throughout space. By selecting what types of atoms to place where, we can strategically alter solvophilicity through distribution of Coulombic charge. This explains how $\mathrm{f}$ can potentially change as a function of molecular weight when the alcohol content stays the same.

Frischknecht and Curro's model for PDMS has less carbon with positive charges per monomer than its insoluble polyether counterparts, $\mathrm{PMO}$ and $\mathrm{PPO}$, and has larger positive charges instead of those negative ones present in even the very relatively positive PEO. This PDMS non-bonded forces trend is not necessarily causal but correlational. Therefore, it is expected that PDMS will be insoluble in nearly all, if not all alcohol contents, and have an associated high surface activity; as the combination of insolubility and reduced surface tension.

Similar logic holds true for methanol. Isopropanol has similar interactions, but one more favorably interacting carbon per molecule, which attracts those on the PDMS molecule. PDMS then should have a suppressed or decreased surface parameter in 2-POH than methanol or ethanol at a given content. Considering this as a dose response curve, for the change in surface parameter per alcohol content added, this tells which alcohol will have the greatest depression in surface activity per amount added.

And so, PDMS will have a larger decrease in surface parameter per fixed ethanol added then methanol added. Again, this predicted trend comes from observing the numerical values of the Coulombic constants with the caveat understanding that the Lennard-Jones forces within the molecule do not change with OPLS-AA atom type for the same bond orders and substituent numbers, i.e., implied hybridizations. 
Such surface parameter heuristics considerations must be made with care and are underpinned by the following logic. The cut-off radius creates a sphere around each atom where non-bonded interactions occur. Therefore, favorable bulk or interface states result from filling the sphere with favorable interactions and eliminating unfavorable interactions. Within these simulations the interactions from other atoms are significant to approximately $1.2 \mathrm{~nm}$. Considering the longest end-to-end polymer considered in this study, a 24 carbon polyethylene, has a $2.8 \mathrm{~nm}$ reach. So even in many partially coiled states it is the case that the carbon from one terminal end does not feel the intramolecular non-bonded forces the carbon from the other terminal end.

The rotation barrier for bonds is a strong indicator of chain flexibility. Since the Si-O rotation barrier is negligible, PDMS can obtain a significantly greater number of configurations in the bulk relative to a 2D interface. Therefore, PDMS possesses one of the strongest entropic driving forces possible to enter the bulk. However, the Coulombic interaction energies of PDMA in water are unfavorable, so the presence of PDMS at the interface is favored since the hemispherical volume above the polymer would not contain any of such unfavorable interactions. Since $\mathrm{k}_{\mathrm{B}} \mathrm{T}$ at room temperature is $539 \mathrm{kcal} / \mathrm{mol}$, the frequency that $\mathrm{C}-\mathrm{O}, \mathrm{Si}-\mathrm{CH}_{3}$ and $\mathrm{C}-\mathrm{CH}_{3}$ bonds are rotating is much less.

Recall from Jorgensen et al. that torsional interaction for eclipsed state hydrogens in ethane adds $2.9 \mathrm{kcal} / \mathrm{mol}$ to the system with respect to the anti-state and, similarly, that methyl hydrogen 1-4 interaction in propane adds $3.2 \mathrm{kcal} / \mathrm{mol}$. Therefore, there are configurationally restrictions associated with such bond rotation energies that restrict the configurationally space achievable by the polymer when it is in the bulk versus in a gas state for example versus a polymer with no dihedral restraint energy but keeping angular, hybridization energies. The decreases in the number of configurations available to the polymer decreases the entropy of the systems the take on those states. The extent nor effect of this entropic hypothetical phenomena on surface activity is not studied in this manuscript. Table 1 indicates like this one indicates the potential number of $\mathrm{O}-\mathrm{H}$ and $\mathrm{H}-\mathrm{O}$ hydrogen bonding sites. Oxygen in can form two hydrogen bonds while $\mathrm{H}$ forms one. However, the addition of oxygen into a polymer backbone typically removes two hydrogen that would be present had a carbon atom occupied the same site. It is critical to consider that the OPLS types of the backbone $\mathrm{C}$ and side $\mathrm{C}$ per monomer are different in the polyalkanes, polyethers and polysilicones. Additionally the hydrogen Coulombic charge depends significantly on the type of carbon to which it is attached. Table 2 indicates the number of backbone carbons and total carbons in the polymer chains which are the focus of this work. Table 3 indicates the force field parameters and numerical data for a united atom simulation of PDMS. The interaction type is shown in the first column, the equilibrium values are presented in the second column and the energetic costs for deviation from equilibrium values are presented in the third column. The bond lengths are an order of magnitude energetically constrained over the hybridization states. In turn, the hybridization states are at least 500 times larger than the dihedral interactions for this structure. Table 4 indicates the following parameters dictate the charge associated with predictions Coulombic interactions for PDMS molecules. Table 5 indicates parameters are present in the non-bonded parameters in the standard OPLS force field. Table 6 indicates the OPLS-AA Force Field Constants in Each of the Polymer Structures. Table 7 indicates the OPLS-AA Force Field Constants in Each of the Solvent Structures. Table 8 indicates Mapping of OPLS-AA atom types onto the Bonded Hybridization Classes. Table 9 indicates each of the atom types within the polyalkane, polyether and solvent structures maps onto one of the following atom classes: $\mathrm{CT}$, $\mathrm{HC}, \mathrm{OH}$ and $\mathrm{HO}$, even $\mathrm{C}=\mathrm{O}$ containing solvents.

\section{Entropy Changes in the Vicinity of Gibb's Surfaces in Dihedrally Restrained Systems}

The dihedral interactions can be 'turned off' in the GROMACS software such that their potentials are not incorporated into the ensemble computation. The polymers in such an ensemble would achieve a wider configurational space. Configurational space limitations have implications in altering the relative entropy of the bulk vs. interface states in dihedral constrained polymers. Non-constrained polymers would have a more significant limitation on the configurational space and as a result of solvophobicity. The author is not aware of any systems

\begin{tabular}{|c|c|c|c|c|c|c|}
\hline & $\begin{array}{c}\text { \# Backbone C per } \\
\text { monomer }\end{array}$ & $\begin{array}{l}\text { \# Side C per } \\
\text { monomer }\end{array}$ & Total \# C per monomer & $\begin{array}{c}\text { Backbone O per } \\
\text { monomer }\end{array}$ & $\begin{array}{c}\text { Backbone Si per } \\
\text { monomer }\end{array}$ & \# H per monomer \\
\hline PE & 2 & 0 & 2 & 0 & 0 & 4 \\
\hline PP & 3 & 1 & 4 & 0 & 0 & 6 \\
\hline PIB & 2 & 2 & 4 & 0 & 0 & 6 \\
\hline PMO & 1 & 0 & 1 & 1 & 0 & 2 \\
\hline PEO & 2 & 0 & 2 & 1 & 0 & 3 \\
\hline P3MO & 3 & 0 & 3 & 1 & 0 & 6 \\
\hline PPO & 2 & 1 & 3 & 1 & 0 & 5 \\
\hline PDMS & 0 & 2 & 2 & 1 & 1 & 6 \\
\hline
\end{tabular}

\#, number.

Table 1: The following chart shows the number of backbone and total carbons added by adding a monomer to the chain length.

\begin{tabular}{|c|c|c|c|c|}
\hline Polymer & Number of monomers & \# Backbone C & \# Side Group C \\
\hline PE & 6-mer & 12 & 0 \\
\hline PE & $12-m e r$ & 24 & 0 & 12 \\
\hline PIB & $6-m e r$ & 12 & 12 & 24 \\
\hline PP & $5-m e r$ & 15 & 5 & 24 \\
\hline PP & $6-m e r$ & 18 & 6 \\
\hline PP & 8-mer & 24 & 8 & 24 \\
\hline
\end{tabular}

\#, number.

Table 2: The following table indicates the number of backbone carbons and total carbons in the polymer chains which are the focus of this work. 
Citation: Mongelli GF (2017) Critical Polyalkane, Polyether, and Polysilicone Structure Differences: Consideration of Polymer Forces from the OPLSAA Standpoint. J Material Sci Eng 6: 313. doi: 10.4172/2169-0022.1000313

Page 4 of 7

\begin{tabular}{|c|c|c|c|}
\hline Bond & Length (nm) & $\begin{array}{l}\text { Electronegativity } \\
\text { difference }\end{array}$ & $\begin{array}{c}\text { Bond energy (kJ/ } \\
\mathrm{mol})\end{array}$ \\
\hline $\mathrm{Si}^{-} \mathrm{O}^{13}$ & 0.165 & 1.7 & 445 \\
\hline $\mathrm{C}-\mathrm{C}^{13}$ & 0.154 & 0 & 346 \\
\hline $\mathrm{Si}-\mathrm{C}^{13}$ & 0.192 & 0.7 & 306 \\
\hline \multicolumn{2}{|c|}{ Bond } & \multicolumn{2}{|c|}{ Rotation barrier $(\mathrm{kcal} / \mathrm{mol})^{20}$} \\
\hline \multicolumn{2}{|c|}{ Si-O } & \multicolumn{2}{|c|}{0.2} \\
\hline \multicolumn{2}{|c|}{$\mathrm{C}-\mathrm{O}$} & \multicolumn{2}{|c|}{2.7} \\
\hline \multicolumn{2}{|c|}{$\mathrm{Si}-\mathrm{CH}_{3}$} & \multicolumn{2}{|c|}{1.6} \\
\hline \multicolumn{2}{|c|}{$\mathrm{C}-\mathrm{CH}_{3}$} & \multicolumn{2}{|c|}{3.6} \\
\hline \multicolumn{2}{|c|}{ Bond } & \multicolumn{2}{|c|}{ Bond angle $\left({ }^{\circ}\right)^{20}$} \\
\hline \multicolumn{2}{|c|}{$\mathrm{Si}-\mathrm{O}-\mathrm{Si}$} & \multicolumn{2}{|c|}{142.5} \\
\hline \multicolumn{2}{|c|}{ O-Si-O } & \multicolumn{2}{|c|}{109} \\
\hline \multicolumn{2}{|c|}{$\mathrm{C}-\mathrm{C}-\mathrm{C}$} & \multicolumn{2}{|c|}{112} \\
\hline Bond & $r_{0}(A)$ & \multicolumn{2}{|c|}{$\mathrm{k}_{\mathrm{b}}\left(\mathrm{kcal} / \mathrm{mol} \bullet \AA^{2}\right)$} \\
\hline $\mathrm{Si}-\mathrm{O}^{20}$ & 1.64 & \multicolumn{2}{|c|}{350.12} \\
\hline $\mathrm{Si}-\mathrm{CH}_{3}^{20}$ & 1.9 & \multicolumn{2}{|c|}{189.65} \\
\hline Angles & $\Theta_{0}\left(\operatorname{deg}^{2}\right)$ & \multicolumn{2}{|c|}{$k_{\theta}\left(k c a l / m_{0 l} \bullet d_{e g}{ }^{2}\right)$} \\
\hline $\mathrm{Si}-\mathrm{O}-\mathrm{Si}^{20}$ & 146.46 & \multicolumn{2}{|c|}{14.14} \\
\hline $\mathrm{O}-\mathrm{Si}-\mathrm{O}^{20}$ & 107.82 & \multicolumn{2}{|c|}{94.5} \\
\hline $\mathrm{CH}_{3}-\mathrm{Si}_{-} \mathrm{CH}_{3}{ }^{20}$ & 109.24 & \multicolumn{2}{|c|}{49.97} \\
\hline $\mathrm{O}-\mathrm{Si}^{-} \mathrm{CH}_{3}^{20}$ & 110.69 & \multicolumn{2}{|c|}{49.97} \\
\hline \multicolumn{2}{|c|}{ Dihedrals } & \multicolumn{2}{|c|}{$k_{t}\left(\mathrm{kcal} / \mathrm{mol}^{20}\right.$} \\
\hline \multicolumn{2}{|c|}{ Si-O-Si-O } & \multicolumn{2}{|c|}{0.225} \\
\hline \multicolumn{2}{|c|}{$\mathrm{Si}-\mathrm{O}-\mathrm{Si}-\mathrm{CH}_{3}$} & \multicolumn{2}{|c|}{0.01} \\
\hline $\begin{array}{l}\text { van der Walls } \\
\text { interaction }\end{array}$ & $\varepsilon(\mathrm{kJ} / \mathrm{mol})$ & \multicolumn{2}{|c|}{$\sigma(\AA)$} \\
\hline $\mathrm{Si}-\mathrm{O}_{2}$ & 2.4468 & 4.2 & 29 \\
\hline $\mathrm{O}-\mathrm{Si}_{2}$ & 0.3347 & 3. & 3 \\
\hline $\mathrm{C}-\mathrm{H}_{3} \mathrm{Si}$ & 0.2594 & 3.38 & 354 \\
\hline $\mathrm{H}-\mathrm{CSi}$ & 0.0962 & 2.8 & 78 \\
\hline
\end{tabular}

Table 3: The force field parameters and numerical data for a united atom simulation of PDMS. The interaction type is shown in the first column, the equilibrium values are presented in the second column and the energetic costs for deviation from equilibrium values are presented in the third column. The bond lengths are an order of magnitude energetically constrained over the hybridization states. In turn, the hybridization states are at least 500 times larger than the dihedral interactions for this structure.

\begin{tabular}{|c|c|}
\hline Atom & $\mathbf{q}(\mathbf{e})$ \\
\hline $\mathrm{Si}$ & 0.7150 \\
\hline $\mathrm{O}$ & -0.4450 \\
\hline $\mathrm{C}$ & -0.2940 \\
\hline $\mathrm{H}$ & 0.0530 \\
\hline
\end{tabular}

Table 4: The following parameters dictate the charge associated with predictions Coulombic interactions for PDMS molecules.

\begin{tabular}{|c|c|c|c|c|}
\hline $\begin{array}{c}\text { OPLS-AA } \\
\text { designation }\end{array}$ & type & $\mathbf{q}(\mathbf{e})$ & $\boldsymbol{\sigma}(\mathbf{A})$ & $\boldsymbol{\varepsilon}$ (kcal/mol) \\
\hline opls_135 & ${\mathrm{C} \mathrm{in} \mathrm{RCH}_{3}}$ & -0.18 & 0.35 & 0.276 \\
\hline opls_136 & $\mathrm{C}$ in $\mathrm{RCH}_{2} \mathrm{R}^{\prime}$ & -0.12 & 0.35 & 0.276 \\
\hline opls_137 & $\mathrm{C}$ in $\mathrm{R}_{3} \mathrm{CH}$ & -0.06 & 0.35 & 0.276 \\
\hline opls_140 & $\mathrm{H}$ & 0.06 & 0.25 & 0.126 \\
\hline opls_139 & $\mathrm{C}$ in $\mathrm{CR}_{4}$ & 0 & 0.35 & 0.276 \\
\hline
\end{tabular}

Table 5: The following parameters are present in the non-bonded parameters in the standard OPLS force field.

\begin{tabular}{|c|c|c|c|c|}
\hline \multicolumn{5}{|c|}{ Polyalkanes } \\
\hline \multicolumn{2}{|r|}{ Name } & \multirow{2}{*}{\begin{tabular}{|l|}
$\mathbf{q}(\mathbf{e})$ \\
-0.18
\end{tabular}} & \multirow{2}{*}{\begin{tabular}{|l|}
$\boldsymbol{\sigma}(\mathbf{n m})$ \\
$3.50 \mathrm{E}-01$ \\
\end{tabular}} & \multirow{2}{*}{\begin{tabular}{|l|}
$\boldsymbol{\varepsilon}(\mathbf{k J} / \mathbf{m o l})$ \\
$2.76 \mathrm{E}-01$ \\
\end{tabular}} \\
\hline opls_135 & $\mathrm{C}$ in $\mathrm{RCH}_{3}$ & & & \\
\hline opls_136 & $\mathrm{C}$ in $\mathrm{RCH}_{2} \mathrm{R}^{\prime}$ & -0.12 & 3.50E-01 & 2.76E-01 \\
\hline opls_137 & $\mathrm{C}$ in $\mathrm{RCH}$ & -0.06 & 3.50E-01 & 2.76E-01 \\
\hline opls_139 & $\mathrm{C}$ in $\mathrm{CR}_{4}$ & 0 & 3.50E-01 & 2.76E-01 \\
\hline opls_140 & $\mathrm{H}$ & 0.06 & 2.50E-01 & $1.26 \mathrm{E}-01$ \\
\hline \multicolumn{5}{|c|}{$\begin{array}{l}\text { Note: Each of the polyalkane carbons have the same LJ forces, but different } \\
\text { coulombics. Even so delineate betweem PE, PP, and PIB. }\end{array}$} \\
\hline \multicolumn{5}{|c|}{$\begin{array}{ll}\text { PMO } \\
\end{array}$} \\
\hline \multicolumn{2}{|r|}{ Name } & $q(e)$ & $\sigma(n m)$ & $\varepsilon(\mathrm{kJ} / \mathrm{mol})$ \\
\hline opls_140 & $\mathrm{H}$ & 0.06 & $2.50 \mathrm{E}-01$ & $1.26 \mathrm{E}-01$ \\
\hline opls_180 & $\mathrm{O}$ (dialkyl ether) & -0.4 & 2.90E-01 & $5.86 \mathrm{E}-01$ \\
\hline opls_181 & $\mathrm{C}\left(\mathrm{H}_{3} \mathrm{OR}\right)$ & 0.11 & 3.50E-01 & 2.76E-01 \\
\hline opls_182 & $\mathrm{C}\left(\mathrm{H}_{2} \mathrm{OR}\right)$ & 0.14 & $3.50 \mathrm{E}-01$ & 2.76E-01 \\
\hline \multicolumn{5}{|c|}{$\begin{array}{l}\text { The carbon attached to oxygen ether has the same LJ forces as the poly-alkane } \\
\text { carbon, but a much more positive charge. This is true in PMO, PEO, PPO } \\
\text { and } \mathrm{P}_{3} \mathrm{MO} \text {. The Coulombic constants are different in each of these cases.More } \\
\text { positive to less positive: } 158,157,182,181,137,136,135\end{array}$} \\
\hline \multicolumn{2}{|r|}{ Name } & $q(e)$ & $\sigma(n m)$ & $\varepsilon(\mathrm{kJ} / \mathrm{mol})$ \\
\hline opls_140 & $\mathrm{H}$ & 0.06 & 2.50E-01 & $1.26 \mathrm{E}-01$ \\
\hline opls_157 & $\mathrm{CH}_{2}$ or $\mathrm{CH}_{3}$ in mono-OH & 0.145 & 3.50E-01 & 2.76E-01 \\
\hline opls_180 & $\mathrm{O}$ (dialkyl ether) & -0.4 & 2.90E-01 & $5.86 \mathrm{E}-01$ \\
\hline opls_181 & $\mathrm{C}\left(\mathrm{H}_{3} \mathrm{OR}\right)$ & 0.11 & 3.50E-01 & 2.76E-01 \\
\hline opls_182 & $\mathrm{C}\left(\mathrm{H}_{2} \mathrm{OR}\right)$ & 0.14 & 3.50E-01 & 2.76E-01 \\
\hline \multicolumn{5}{|c|}{ PPO } \\
\hline \multicolumn{2}{|r|}{ Name } & $q(e)$ & $\sigma(\mathrm{nm})$ & $\varepsilon(\mathrm{kJ} / \mathrm{mol})$ \\
\hline opls_135 & $\mathrm{C}$ in $\mathrm{RCH}_{3}$ & -0.18 & 3.50E-01 & $2.76 \mathrm{E}-01$ \\
\hline opls_136 & $\mathrm{C}$ in $\mathrm{RCH}_{2} \mathrm{R}^{\prime}$ & -0.12 & 3.50E-01 & 2.76E-01 \\
\hline opls_140 & $\mathrm{H}$ & 0.06 & $2.50 \mathrm{E}-01$ & 1.26E-01 \\
\hline opls_157 & $\mathrm{CH}_{2}$ or $\mathrm{CH}_{3}$ in mono-OH & 0.145 & 3.50E-01 & 2.76E-01 \\
\hline opls_182 & $\mathrm{C}\left(\mathrm{H}_{2} \mathrm{OR}\right)$ & 0.14 & 3.50E-01 & 2.76E-01 \\
\hline opls_180 & $\mathrm{O}$ (dialkyl ether) & -0.4 & 2.90E-01 & $5.86 \mathrm{E}-01$ \\
\hline \multicolumn{5}{|c|}{ P3MO } \\
\hline \multicolumn{2}{|r|}{ Name } & $q(e)$ & $\sigma(n m)$ & $\varepsilon(\mathrm{kJ} / \mathrm{mol})$ \\
\hline opls_135 & $\mathrm{C}$ in $\mathrm{RCH}_{3}$ & -0.18 & 3.50E-01 & $2.76 \mathrm{E}-01$ \\
\hline opls_136 & $\mathrm{C}$ in $\mathrm{RCH}_{2} \mathrm{R}^{\prime}$ & -0.12 & 3.50E-01 & $2.76 \mathrm{E}-01$ \\
\hline opls_137 & $\mathrm{C}$ in $\mathrm{RCH}$ & -0.06 & 3.50E-01 & 2.76E-01 \\
\hline opls_140 & $\mathrm{H}$ & 0.06 & $2.50 \mathrm{E}-01$ & 1.26E-01 \\
\hline opls_182 & $\mathrm{C}\left(\mathrm{H}_{2} \mathrm{OR}\right)$ & 0.14 & 3.50E-01 & 2.76E-01 \\
\hline opls_180 & $\mathrm{O}$ (dialkyl ether) & -0.4 & 2.90E-01 & $5.86 \mathrm{E}-01$ \\
\hline
\end{tabular}

Table 6: The OPLS-AA Force Field Constants in Each of the Polymer Structures.

in which entropy effects are the proven majority or strongest impacting driving forces for solvophilicity changes. The relative entropies of the polymers in bulk and surface states can be determined from a fundamental relationship with the free energy in the ensemble of choice. Bulk systems can be simulated in NPT/Isothermal-isobaric ensemble and slab systems in NVT/Canonical ensemble. For the former, the key potential relationship is $\Delta S(N, p, T)=(p V-\Delta G) / T$ and for the latter: $\Delta S(N, V, T)=(-\Delta A) / \mathrm{T}$.

The surface excess free energy [13] or free energy of hydration [19] have components which are derived from the strength and number of hydrogen bonds and the remaining potentials which do not go into forming hydrogen bonds. That is to say that there may be excess attractive energy that brings atoms closer than required to trip the critical hydrogen bond distance criterion [20-22]. With ensemble theory we should be able to calculate both the energy and the excess distance. 


\begin{tabular}{|c|c|c|c|c|}
\hline \multicolumn{5}{|c|}{$\mathrm{MeOH}$} \\
\hline & & $q(e)$ & $\sigma(\mathrm{nm})$ & $\varepsilon(\mathrm{kJ} / \mathrm{mol})$ \\
\hline opls_135 & $\mathrm{C}$ in $\mathrm{RCH} 3$ & -0.18 & 3.50E-01 & 2.76E-01 \\
\hline opls_140 & $\mathrm{H}$ & 0.06 & 2.50E-01 & 1.26E-01 \\
\hline opls_154 & $\mathrm{O}$ in mono-OH & -0.683 & 3.12E-01 & 7.11E-01 \\
\hline \multicolumn{5}{|c|}{ EtOH } \\
\hline & & $q(e)$ & $\sigma(n m)$ & $\varepsilon(\mathrm{kJ} / \mathrm{mol})$ \\
\hline opls_135 & $\mathrm{C}$ in $\mathrm{RCH} 3$ & -0.18 & 3.50E-01 & 2.76E-01 \\
\hline opls_140 & $\mathrm{H}$ & 0.06 & 2.50E-01 & 1.26E-01 \\
\hline opls_154 & $\mathrm{O}$ in mono-OH & -0.683 & 3.12E-01 & 7.11E-01 \\
\hline opls_155 & $\mathrm{H}$ in mono-OH & 0.418 & 0 & 0 \\
\hline opls_157 & $\begin{array}{l}\mathrm{CH} 2 \text { or } \mathrm{CH} 3 \text { in } \\
\text { mono-OH }\end{array}$ & 0.145 & $3.50 \mathrm{E}-01$ & 2.76E-01 \\
\hline \multicolumn{5}{|c|}{$2 \mathrm{POH}$} \\
\hline & & $q(e)$ & $\sigma(\mathrm{nm})$ & $\varepsilon(\mathrm{kJ} / \mathrm{mol})$ \\
\hline opls_135 & $\mathrm{C}$ in $\mathrm{RCH} 3$ & -0.18 & 3.50E-01 & $2.76 \mathrm{E}-01$ \\
\hline opls_140 & $\mathrm{H}$ & 0.06 & 2.50E-01 & 1.26E-01 \\
\hline opls_154 & $\mathrm{O}$ in mono-OH & -0.683 & 3.12E-01 & 7.11E-01 \\
\hline opls_155 & $\mathrm{H}$ in mono-OH & 0.418 & 0 & 0 \\
\hline opls_157 & $\begin{array}{l}\mathrm{CH} 2 \text { or } \mathrm{CH} 3 \text { in } \\
\text { mono-OH }\end{array}$ & 0.145 & $3.50 \mathrm{E}-01$ & 2.76E-01 \\
\hline \multicolumn{5}{|c|}{ Acetone } \\
\hline & & $q(e)$ & $\sigma(\mathrm{nm})$ & $\varepsilon(\mathrm{kJ} / \mathrm{mol})$ \\
\hline opls_135 & $\mathrm{C}$ in $\mathrm{RCH} 3$ & -0.18 & 3.50E-01 & 2.76E-01 \\
\hline opls_140 & $\mathrm{H}$ & 0.06 & $2.50 \mathrm{E}-01$ & 1.26E-01 \\
\hline opls_235 & $\mathrm{C}$ in $\mathrm{C}-\mathrm{OH}$ & 0.5 & 3.75E-01 & 4.39E-01 \\
\hline opls_236 & $\mathrm{O}$ in $\mathrm{C}=\mathrm{O}$ & -0.5 & 2.96E-01 & 8.79E-01 \\
\hline \multicolumn{5}{|c|}{ Acetoin } \\
\hline & Name & $q(e)$ & $\sigma(\mathrm{nm})$ & $\varepsilon(\mathrm{kJ} / \mathrm{mol})$ \\
\hline opls_135 & $\mathrm{C}$ in $\mathrm{RCH} 3$ & -0.18 & 3.50E-01 & 2.76E-01 \\
\hline opls_140 & $\mathrm{H}$ & 0.06 & $2.50 \mathrm{E}-01$ & 1.26E-01 \\
\hline opls_154 & $\mathrm{O}$ in mono-OH & -0.683 & 3.12E-01 & 7.11E-01 \\
\hline opls_155 & $\mathrm{H}$ in mono-OH & 0.418 & 0 & 0 \\
\hline opls_157 & $\begin{array}{l}\mathrm{CH} 2 \text { or } \mathrm{CH} 3 \text { in } \\
\text { mono- } \mathrm{OH}\end{array}$ & 0.145 & $3.50 \mathrm{E}-01$ & 2.76E-01 \\
\hline opls_235 & $\mathrm{C}$ in $\mathrm{C}-\mathrm{OH}$ & 0.5 & 3.75E-01 & 4.39E-01 \\
\hline opls_236 & $\mathrm{O}$ in $\mathrm{C}=\mathrm{O}$ & -0.5 & 2.96E-01 & 8.79E-01 \\
\hline \multicolumn{5}{|c|}{$\mathrm{HOH}$} \\
\hline & Name & $q(e)$ & $\sigma(\mathrm{nm})$ & $\varepsilon(\mathrm{kJ} / \mathrm{mol})$ \\
\hline $\begin{array}{l}\text { OW_spc } \\
\text { (opls_795) }\end{array}$ & $O$ in water & -0.8476 & 3.22E-01 & 5.86E-01 \\
\hline $\begin{array}{l}\text { HW_spc } \\
\text { (opls_796) }\end{array}$ & $\mathrm{H}$ in water & 0.4238 & 0 & 0 \\
\hline
\end{tabular}

Table 7: The OPLS-AA Force Field Constants in Each of the Solvent Structures.

\begin{tabular}{|c|c|}
\hline $\mathrm{CH}_{1}$ & opls_137 \\
\hline $\mathrm{CH}_{2}$ & opls_136 \\
\hline $\mathrm{CH}_{3}$ & opls_135 \\
\hline $\mathrm{H}$ & opls_140 \\
\hline $\mathrm{CC}_{4}$ & opls_139 \\
\hline $\mathrm{OC}_{2}$ & opls_180 \\
\hline $\mathrm{C}_{3} \mathrm{O}$ & opls_181 \\
\hline $\mathrm{C}_{2} \mathrm{O}$ & opls_182 \\
\hline $\mathrm{Si}$ & Ref 20 \\
\hline $\mathrm{C}-\mathrm{Si}$ & Ref 20 \\
\hline $\mathrm{O}-\mathrm{Si}$ & Ref 20 \\
\hline $\mathrm{H}-\mathrm{Si}$ & Ref 20 \\
\hline
\end{tabular}

Table 8: Mapping of OPLS-AA atom types onto the Bonded Hybridization Classes.

\section{On considering the differences between $\mathrm{O}$ and $\mathrm{C}$ as backbone sites}

Plotting the angle constants is not particularly helpful from a conceptual standpoint since the $\mathrm{C} / \mathrm{Si}$ systems are expected to be tetrahedral and the deviations to two $\mathrm{C}$ vs. two $\mathrm{Si}$ are very minute when $\mathrm{O}$ is connected [23]. Compare C-C-C to O-Si-O. These differences are 111.5 deg between $\mathrm{O}$ and 107.82 , respectively. However, the $\mathrm{O}$ connected to two C vs. two Si is of note- 109.5 deg vs. 146.5, respectively. They will imply changes about where that atoms fall and impact the LJ and Coulombic strength. Note that the angular hybridization angles from refs. 19 and 20 are several degrees of from one another [24,25].

Additionally, the substitution of a carbon for an oxygen along the polymer backbone decrease the coordination number of a particular site, decreasing steric restrictions and increasing the entropy of the system [26]. This could facilitate solvation in the case of PEO, which may have unfavorable or weakly favorable aqueous Coulombic interactions.

\section{On the differences between $\mathrm{Si}$ and $\mathrm{C}$ as backbone sites}

While carbon takes on negative Coulombic charge in polyalkane systems, and small positive charge in polyether systems when bonded to oxygen, carbon in silicon systems takes an even larger negative value than it does in polyalkanes [27]. The silicon atom in silicones takes a large positive value, which is larger than carbon's positive value in ethers. The LJ interactions of all atoms in PDMS, including preferred placement and relative energetic cost of deviations from set distances, are large and indicate that PDMS is very bulky relative to the other polymer and solvent molecules. Therefore when it is placed in the vicinity of a large number of molecules of a certain type, it will destabilize the system relative to it not being present. Placement of PDMS at the interface will minimize the number of molecules and the volume of the bulk that is affected by its destabilizing presence [28].

\section{Conclusions}

The relative strengths and number of these interactions will impose limits on the configurational spaces achievable by otherwise flexible polymers and are further impacted by LJ and Coulombic interactions of connected and adjacent atoms within the molecule.

Even though the dihedral interactions look similar within the polyethers, and the energy differences may be small from dihedral interactions relative to $k_{B}^{*} T$, how such energies are modified by the $L J$ and Coulombic interactions - which are significantly different within the poly-ether series -- is non-trivial and may significantly restrict configuration space in some cases. Those cases are the monomers with more backbone sites per monomer, such as P3MO and PPO. PMO has very little dihedral restriction, however, it does not likely have enough carbons per monomer to induce a strong enough favorable nonbonded attractive interaction with the solvents until higher alcohol contents than other polymers.

Within this manuscript, the key heuristics linking the OPLS-AA force field in the context of polymeric materials to the free energy of solvophility, and therefore surfactantability, are described. The possible explanations for detailing the unique role of (i) dihedral interactions in configurational restraint creating an entropic driving force for solvation and/or (ii) the Coulombic charge differences in carbon bonded to different types and numbers of heteroatoms are key in considering PMO, PEO, PPO, and PDMS. Future work includes the simulation of such materials using the published OPLS-AA force 
Citation: Mongelli GF (2017) Critical Polyalkane, Polyether, and Polysilicone Structure Differences: Consideration of Polymer Forces from the OPLSAA Standpoint. J Material Sci Eng 6: 313. doi: 10.4172/2169-0022.1000313

Page 6 of 7

\begin{tabular}{|c|c|c|c|c|c|c|c|c|c|}
\hline \multicolumn{4}{|c|}{ Polyalkanes } & \multirow{2}{*}{$\begin{array}{l}\mathrm{CO}(\mathrm{KJ} / \mathrm{mol}) \\
2.9288\end{array}$} & \multirow{2}{*}{\begin{tabular}{|l|} 
C1(KJ/mol) \\
-1.4644
\end{tabular}} & \multirow{2}{*}{$\begin{array}{l}\text { C2(KJ/mol) } \\
0.2092\end{array}$} & \multirow{2}{*}{$\begin{array}{l}\text { C3(KJ/mol) } \\
-1.6736\end{array}$} & \multirow{2}{*}{$\begin{array}{l}\mathrm{C} 4(\mathrm{KJ} / \mathrm{mol}) \\
0\end{array}$} & \multirow{2}{*}{$\begin{array}{l}\text { C5(KJ/mol) } \\
0\end{array}$} \\
\hline CT & CT & CT & CT & & & & & & \\
\hline CT & CT & CT & $\mathrm{HC}$ & 0.9665 & 2.89951 & 0 & -3.86601 & 0 & 0 \\
\hline $\mathrm{HC}$ & CT & CT & $\mathrm{HC}$ & 0.66525 & 1.99576 & 0 & -2.66102 & 0 & 0 \\
\hline \multicolumn{10}{|l|}{ PMO } \\
\hline OS & CT & OS & CT & -5.35761 & 13.61683 & 8.44331 & -16.7025 & 0 & 0 \\
\hline OS & CT & OS & $\mathrm{HC}$ & 1.58992 & 4.76976 & 0 & -6.35968 & 0 & 0 \\
\hline \multicolumn{10}{|l|}{ PEO } \\
\hline $\mathrm{CT}$ & OS & CT & OS & 5.35761 & 13.61683 & 8.44331 & -16.7025 & 0 & 0 \\
\hline CT & CT & OS & CT & 1.71544 & 2.84512 & 1.046 & -5.60656 & 0 & 0 \\
\hline $\mathrm{HC}$ & CT & CT & OS & 0.97905 & 2.93716 & 0 & -3.91622 & 0 & 0 \\
\hline $\mathrm{HC}$ & CT & OS & CT & & & & & & \\
\hline \multicolumn{10}{|l|}{ PPO } \\
\hline OS & CT & CT & OS & -1.1506 & 1.1506 & 0 & 0 & 0 & 0 \\
\hline $\mathrm{HC}$ & CT & CT & OS & 0.97905 & 2.98716 & 0 & -3.91622 & 0 & 0 \\
\hline CT & CT & CT & OS & 2.87441 & 0.58158 & 2.092 & -5.54799 & 0 & 0 \\
\hline CT & CT & CT & $\mathrm{HC}$ & 0.9665 & 2.89951 & 0 & -3.86601 & 0 & 0 \\
\hline $\mathrm{HC}$ & CT & OS & CT & 1.58992 & 4.76976 & 0 & -6.35968 & 0 & 0 \\
\hline \multicolumn{10}{|l|}{ P3MO } \\
\hline CT & CT & CT & OS & 2.87441 & 0.58158 & 2.092 & -5.54799 & 0 & 0 \\
\hline $\mathrm{HC}$ & CT & CT & OS & 0.97905 & 2.93716 & 0 & -3.91622 & 0 & 0 \\
\hline CT & CT & os & CT & 1.71544 & 2.84512 & 1.046 & -5.60656 & 0 & 0 \\
\hline $\mathrm{HC}$ & CT & $\mathrm{CT}$ & $\mathrm{HC}$ & 0.66525 & 1.99576 & 0 & -2.66102 & 0 & 0 \\
\hline CT & OS & CT & $\mathrm{HC}$ & 1.58992 & 4.76976 & 0 & -6.35968 & 0 & 0 \\
\hline PDMS & see ref 33, p 20344 & & ref $35,17,42$ & $\mathrm{CO}(\mathrm{KJ} / \mathrm{mol})$ & $\mathrm{C} 1(\mathrm{KJ} / \mathrm{mol})$ & $\mathrm{C} 2(\mathrm{KJ} / \mathrm{mol})$ & $\mathrm{C} 3(\mathrm{KJ} / \mathrm{mol})$ & $\mathrm{C} 4(\mathrm{KJ} / \mathrm{mol})$ & C5(KJ/mol) \\
\hline $\mathrm{Si}$ & $\mathrm{O}$ & $\mathrm{Si}$ & $\mathrm{O}$ & -0.41 & 0.2731 & 0.21968 & 0 & 0 & 0 \\
\hline $\mathrm{Si}$ & $\mathrm{O}$ & $\mathrm{Si}$ & C & 0 & 0 & -0.05706 & 0 & 0 & 0 \\
\hline $\mathrm{O}$ & $\mathrm{Si}$ & C & $\mathrm{H}$ & 0 & 0 & -0.15 & 0 & 0 & 0 \\
\hline C & $\mathrm{Si}$ & C & $\mathrm{H}$ & 0 & 0 & -0.15 & 0 & 0 & 0 \\
\hline
\end{tabular}

Table 9: Each of the atom types within the polyalkane and solvent structures maps onto one of the following atom classes: $\mathrm{CT}, \mathrm{HC}, \mathrm{OH}$ and $\mathrm{HO}$, even $\mathrm{C}=\mathrm{O}$ containing solvents.

fields, and subsequent analysis of the relative position of such materials with respect to interfaces. These interactions lead to key changes in the surface excess free energy and free energy of solvation, which will be discussed in a separate work in the near future.

\section{Acknowledgements}

I would like to acknowledge the National Science Foundation Award Abstract \#1159327.

\section{References}

1. Kaminski GA, Friesner RA, Tirado-Rives J (2001) Conference: Symposium on Molecular Dynamics- The Next Millenium Locations. J Phys Rev Chem B 105 : 6474-6487.

2. Damm W, Frontera A, Tirado-Rives J, Jorgensen WL (1997) OPLS all-atom force field for carbohydrates. J Comput Chem 18: 1955-1970.

3. Rizzo RC, Jorgensen WL (1999) OPLS all-atom model for amines: Resolution of the amine hydration problem. J Am Chem Soc 121: 4827-4836.

4. Stern HA, Kaminski GA, Banks JL, Zhou R, Berne BJ, et al. (1999) Fluctuating charge, polarizable dipole and combined models: Parameterization from ab initio quantum chemistry. J Phys Chem B 103: 4730-4737.

5. McDonald NA, Jorgensen WL (1998) Development of an all-atom force field for heterocycles. Properties of liquid pyrrole, furan, diazoles, and oxazoles. J Phys Chem B 102: 8049-8059.

6. Kaminski GA, Jorgensen WL (1996) Performance of the Amber 94, MMFF94, and OPLS-AA force fields for modelling organic liquids. J Phys Chem 100: 18010-18013.

7. Mann EK, Langevin D, Hennon S, Meunier J, Lee LT (1994) Mixed Polymer Surfactant Layers at the Air-Water Interface. Ber Bunsen Phys Chem 98: 519-520.

8. Kinoshita M (2003) Interaction between surfaces with solvophobicity or solvophilicity immersed in a solvent. J Chem Phys 118: 8969-8981.
9. Specialty Surfactants Market - Global Scenario, Raw Material And Consumption Trends, Industry Analysis, Size, Share \& Forecast 2011-2017.

10. Baney RH, Voight CE, Mantelle JW (1977) Structure-Solubility Relationships in Polymers. Seymour Academic Press, NY.

11. Jorgensen W, Tirado-Rives J (1988) The OPLS functions for protiens, energy minimizations for crystals of cyclic peptides and crambin. J Am Chem Soc 110 1657-1666.

12. Sides SW, Curro J, Grest GS, Stevens ML, Soddermann T, et al. (2002) Structure of Poly(dimethylsiloxane) Melts: Theory, Simulations and Experiment Macromolecules 35: 6455-6465.

13. Frischknecht AL, Curro JG (2003) Improved United Atom Force Field for Poly(dimethylsiloxane). Macromolecules 36: 2122-2129.

14. Kinoshita M (2003) Development and testing of the OPLS all-atom force field on conformational energetics and properties of organic liquids. J Chem Phys 118: 8969-8981.

15. Smith GD, Bedrov D, Borodin O (2000) Molecular dynamics simulation study of hydrogen bonding in aqueous poly(ethylene oxide) solutions. Phys Rev Lett 85: 5583.

16. Smith GD, Bedrov D (2003) Roles of enthalpy, entropy and hydrogen bonding in the lower critical solution temperature behavior of poly(ethylene oxide)/wate solutions. J Phys Chem B 107: 3095.

17. Bedrov D, Smith GD (2002) A molecular dynamics simulation study of the influence of hydrogen bonding and polar interactions on hydration and conformations of a poly(ethylene oxide) oligomer in dilute aqueous solution Macromolecules 35: 5712-5719.

18. Dormidontova EE (2002) Role of competitive PEO-water and water-water hydrogen bonding in aqueous solution PEO behavior. Macromolecules 35 987-1001.

19. Frischknecht AL, Curro JG (2003) Improved United Atom Force Field fo Poly(dimethylsiloxane). Macromolecules 36: 2122-2129. 
Citation: Mongelli GF (2017) Critical Polyalkane, Polyether, and Polysilicone Structure Differences: Consideration of Polymer Forces from the OPLSAA Standpoint. J Material Sci Eng 6: 313. doi: 10.4172/2169-0022.1000313

Page 7 of 7

20. Sides SW, Curro J, Grest GS, Stevens ML, Soddermann T, et al. (2002) Structure of Poly(dimethylsiloxane) Melts: Theory, Simulations and Experiment. Macromolecules 35: 6455-6465.

21. Smith GD, Bedrov D, Borodin O (2000) Molecular dynamics simulation study of hydrogen bonding in aqueous poly(ethylene oxide) solutions. Phys Rev Lett 85: 5583.

22. Smith GD, Bedrov D (2003) Roles of enthalpy, entropy and hydrogen bonding in the lower critical solution temperature behavior of poly(ethylene oxide)/water solutions. J Phys Chem B 107: 3095-3097.

23. Bedrov D, Smith GD (2002) Multifaceted Synthetic Route to Functional Polyacrylates by Transesterification of Poly(pentafluorophenyl acrylates). Macromolecules 35: 5712.
24. Dormidontova EE (2002) Role of competitive PEO-water and water-water hydrogen bonding in aqueous solution PEO behavior. Macromolecules 35 987-1001.

25. Frischknecht AL, Curro JG (2003) Improved United Atom Force Field for Poly(dimethylsiloxane). Macromolecules 36: 2122-2129.

26. Mitropoulos SC (2008) What is a surface excess? J Eng Sci Tech Rev 1: 1-3.

27. Shah PP, Roberts CJ (2008) Solvation in mixed aqueous solvents from a thermodynamic cycle approach. J Phys Chem Lett 112: 1049-1052.

28. Chen B, Siepmann JI (1999) Transferable potentials for phase equilibria Explicit hydrogen description of normal alkanes. J Phys Chem B 25: 53705379. 